\title{
When do we need to suspect maturity onset diabetes of the young in patients with type 2 diabetes mellitus?
}

Özlem Üstay ${ }^{1}$

https://orcid.org/0000-0002-7993-955X

Tugçe Apaydın'

https://orcid.org/0000-0001-9277-8669

Onur Elbasan'

https://orcid.org/0000-0001-8580-9471

Hamza Polat ${ }^{2}$

https://orcid. org/0000-0003-0833-9968

Gizem Günhan ${ }^{3}$

https://orcid.org/0000-0001-6592-7171

Ceyda Dincer ${ }^{1}$

https://orcid.org/0000-0003-3680-3051

Lamia Șeker ${ }^{3}$

https://orcid.org/0000-0003-3838-1753

Esra Arslan Ates ${ }^{2}$

https://orcid.org/0000-0001-5552-8134

Ayşegül Yabacı ${ }^{4}$

https://orcid. org/0000-0002-5813-3397

Ahmet Ilter Güney ${ }^{2}$

https://orcid.org/0000-0002-1661-1282

Dilek Gogas Yavuz'

https://orcid. org/0000-0002-0075-6313

\begin{abstract}
Objetivo: Maturity onset diabetes of the young (MODY) patients have clinical heterogeneity as shown by many studies. Thus, often it is misdiagnosed to type 1 or type 2 diabetes(T2DM). The aim of this study is to evaluate MODY mutations in adult T2DM patients suspicious in terms of MODY, and to show clinical and laboratory differences between these two situations. Subjects and methods: In this study, we analyzed 72 type 2 diabetic patients and their relatives (35F/37M) who had been suspected for MODY and referred to genetic department for mutation analysis. The gene mutations for MODY have been assessed in the laboratory of Marmara University genetics. Totally 67 (32F/35M; median age 36.1) diabetic patients were analyzed for 7 MODY mutations. Twelve patients who have uncertain mutation (VUS) were excluded from study for further evaluation. MODY $(+)$ (n:30) patients and T2DM patients ( $\mathrm{n}: 25)$ were compared for clinical and laboratory parameters. Results: In MODY(+) subjects, mutations in GCK (MODY 2) (n:12; 40\%) were the most common followed by HNF4A (MODY 1) (n:4; 13.3\%). Diabetes diagnosis age was younger in MODY(+) group but not statistically significant. Sixty-six percent of MODY(+) subjects had diabetes history at 3-consecutive generations in their family compared with $28 \%$ of T2DM patients statistically significant ( $p: 0.006$ ). Gender, BMI, C-peptide, HbA1c, lipid parameters, creatinine, GFR, microalbuminuria, vitamin D and calcium were not statistically different between the groups. Conclusion: According to present study results, MODY mutation positivity is most probable in young autoantibody (-) diabetic patients diagnosed before 30 years of age, who have first degree family history of diabetes.
\end{abstract}

Keywords

MODY; maturity onset diabetes of the young; early onset type 2 diabetes
${ }^{1}$ Marmara University School of Medicine, Endocrinology and Metabolism, Istanbul, Turkey

${ }^{2}$ Marmara University School of Medicine, Medical Genetics, Istanbul, Turkey ${ }^{3}$ Marmara University School of Medicine, Internal Medicine, Istanbul, Turkey ${ }^{4}$ Bezmialem Vakif University School of Medicine, Department of Biostatistics, Istanbul, Turkey

Correspondence to:

Özlem Üstay

Marmara University Pendik Training and Research Hospital

Fevzi Cakmak, Muhsin

Yazicioglu Cd No:10

34899 Pendik

Istanbul, Turkey

drozlemustay@gmail.com

Received on Sept/29/2020 Accepted on Sept/22/2021

DOI: 10.20945/2359-3997000000431 


\section{INTRODUCTION}

$\mathrm{T}$ ype 2 diabetes mellitus (T2DM) incidence has been increasing in Turkey, as well as globally, and has begun to be seen at much earlier ages. Some of these patients have a genetic disposition for diabetes, just like their relatives. Maturity onset diabetes of the young (MODY) is an autosomal dominant inherited, common monogenic form of diabetes $(1,2)$. Incidence of MODY varies by region ranging from $2 \%$ to $5 \%$ of all diabetic patients $(1,3)$. MODY is caused by over 800 mutations in 14 different MODY-related genes (4-8). The most common mutations are found in GCK (glucokinase), HNFIA (hepatocyte nuclear factor-lalpha) and HNF4A (hepatocyte nuclear factor4alpha) $(2,9)$.

Many studies have shown the clinical heterogeneity of MODY patients (10-13). Thus, MODY is often misdiagnosed as type 1 or type 2 diabetes. The clinical diagnosis of MODY is based on young onset (before the age of 25), presence of diabetes in at least 3 consecutive generations, absence of $\beta$-cell autoantibodies, and relatively preserved endogenous insulin secretion, according to some studies $(14,15)$. Since MODY is diagnosed at an early age, it is often confused with early-onset T2DM. Early-onset T2DM is recognized as a special kind of type 2 diabetes which was diagnosed at a young age (30-45 years) with various genetic tendencies. Although type 2 diabetes is a disease related to aging, the prevalence of early-onset T2DM in adults has increased globally (16). Due to overlapping clinical features, distinguishing MODY from earlyonset T2DM is often difficult. The molecular diagnosis and classification of MODY patients are essential for a correct treatment decision and in the judgment of the prognosis. Genetic testing is highly specific and sensitive; therefore, it represents the gold standard for diagnosing MODY. However, genetic testing is an expensive procedure which renders it an inaccessible tool for diagnosing MODY. Thus, careful consideration is required when determining which patients should be tested; and considerable efforts have been made to investigate nongenetic or clinical markers in order to facilitate the differential diagnosis of MODY.

Studies have shown that GCK mutations are common in Turkish pediatric cohorts, which represent one-quarter of MODY cases of all diabetics in childhood (17). The pediatric population usually has a higher risk of type 1 diabetes mellitus (TIDM), and their clinical presentation is quite different in young patients from that of T2DM patients. Thus, it is relatively easy to differentiate these two diseases in pediatric groups. However, insufficient number of studies have been conducted related to the clinical differences between MODY and early-onset T2DM in adult populations. Moreover, contradictory data about the most common MODY mutation types appears in recent literature. GCK and HNFIA mutations are known to be the most common mutations, especially in Europe and North America $(2,9,18)$. According to the limited data available in Turkey, HNFIA is regarded as the most common mutation in MODY patients, however there is insufficient information about the clinical characteristics of early-onset T2DM patients and differences from MODY (19).

The aim of this study was to evaluate MODY mutations in adult T2DM patients who were suspected of MODY, and to show clinical and laboratory differences between these two types of diabetes.

\section{SUBJECTS AND METHODS}

In this study, we analyzed 72 T2DM patients and their relatives $(35 \mathrm{~F} / 37 \mathrm{M})$, followed at the endocrinology out-patient clinic of Marmara University Hospital, who had been suspected of MODY and referred to the genetic department for mutation analysis. Although the clinical diagnosis of MODY is usually based-on young onset before the age of 25 , presence of diabetes in at least 3 consecutive generations, absence of $\beta$-cell autoantibodies (anti-GAD antibody, anti-islet cell antibody), and relatively preserved endogenous insulin secretion, the specific clinical criteria for MODY diagnosis are still not very clear. In our study, we enrolled all patients referred to the genetic department for MODY mutation, thus not all the patients met all the clinical criteria for MODY diagnosis described in the literature.

The study was approved by the local ethics committee of Marmara University School of Medicine (protocol number 09.2020.01).

All patients were invited to the endocrinology outpatient clinic and were evaluated for age, duration of diabetes, age at diagnosis, micro and macro complications of diabetes, family history of diabetes, drug usage (type and exposure time), body mass index (BMI), and blood pressure; and were tested for fasting plasma glucose, fasting serum C-peptide level, glycosylated hemoglobin ( $\mathrm{HbAlc})$, lipid profile 
(total, LDL-cholesterol, HDL-cholesterol and triglycerides), islet cell autoantibodies (ICAs), glutamic acid decarboxylase (GAD) autoantibodies and insulin antibodies (IAAs).

Positive results for GAD autoantibodies appeared in 5 out of 72 patients $(7.7 \%)$. Only one of them had a mutation for MODY, and all of these 5 patients were diagnosed with latent autoimmune diabetes of adults (LADA).

The gene mutations for MODY were assessed in the Marmara University genetics laboratory. In total, 67 (32 F/35 M; median age 36.1) diabetes patients were analyzed for 7 MODY mutations. They were categorized according to the pathogenicity identification as pathogenic MODY (+), variant of uncertain significance (VUS), and without any mutation (T2DM). Fifteen patients who had VUS mutations were excluded from the study for further evaluation. MODY (+) patients (n $=27)$ and T2DM patients $(\mathrm{n}=25)$ were compared in terms of clinical and laboratory parameters.

\section{Genetic analysis}

All patients were informed in person and their written consent was obtained. Genomic DNA was isolated from peripheral blood leucocytes using the QIAamp DNA Blood Mini QIAcube Kit (Qiagen, Hilden, Germany), according to the manufacturer's protocols. All coding exons and exon-intron boundaries of seven genes that were associated with MODY (KCNJ11, ABCC8, INS, GCK, HNF4A, HNFIA, HNFIB) were amplified using the Multiplicom MODY MasterDx (Agilent, CA, USA) kit. Prepared library was sequenced on the Illumina Miseq platform (Illumina Inc., San Diego, CA, USA). The data were analyzed by the Sophia DDM data analysis software. In order to call variants, sequencing data was aligned to human reference genome, hg19. After amplifying targeted regions using designed primers, Sanger sequencing on ABI Prism 3500 Genetic Analyzer (Thermo Fisher Scientific, MA USA) was performed for the confirmation of the detected variants and segregation analysis. Novel variations were classified according to the American College of Medical Genetics and Genomics criteria (20). Mutation Taster, The Sorting Intolerant from Tolerant (SIFT) and deleterious annotation of genetic variants using neural networks (DANN) were used for computational pathogenicity prediction (21). The data of minor allele frequencies of variants were obtained from GnomAD (22).

\section{Statistical analysis}

The distribution of the data was examined using the Shapiro-Wilk test. Normally distributed data between the two groups were compared with an independent samples $t$ test, and non-normally distributed data between the two groups were compared with the MannWhitney $U$ test. The difference between categorical variables was examined with Pearson's $X^{2}$ test, and Fisher's exact test. The descriptive statistics of the data are presented as mean and standard deviation, median (min-max), and $\mathrm{n}(\%)$. All statistical analyses were conducted in the IBM SPSS Statistics 22.0 program with a significance level of 0.05 .

\section{RESULTS}

We evaluated 67 patients who were eligible for this study design. Twenty-seven of these patients $(40.3 \%)$ were found to have pathogenic mutations grouped as MODY $(+)$, and 15 were found to have VUS mutations $(22.4 \%)$ and were excluded from the study. In MODY $(+)$ subjects, mutations in GCK (MODY 2) were the most common followed by HNF4A (MODY 1). All pathogenic and likely pathogenic mutation types in the mutation-positive group were given in detail in Table 1 (23-33).

We detected four novel variations which were predicted to be likely pathogenic according to the ACMG guidelines (20). The novel likely pathogenic variants and pathogenicity evaluation details were presented in Table 2. Related variations were segregated with the disease in three families. However, the patient carrying the HNF4A c.110T>C (p.Leu37Pro) variation declared that no family members were diagnosed with MODY, hence we were not able to screen the parents for MODY.

In MODY (+) subjects, GCK mutations (MODY 2) ( $\mathrm{n}=12 ; 44.4 \%)$ were the most common followed by HNF4A mutations (MODY 1$)(\mathrm{n}=3 ; 11.1 \%)$. When we compared MODY $(+)(\mathrm{n}=27)$ and T2DM $(\mathrm{n}=$ $25)$ groups according to the laboratory parameters, no differences between the groups were found. C-peptides, HbAlc, lipid parameters, creatinine, glomerular filtration rate (GFR), microalbuminuria, vitamin $\mathrm{D}$, and calcium were not statistically different between the groups (Table 3 ).

Regarding demographic parameters and diabetes history, median age was 36.1 years, and there appeared to be no difference between the groups. BMI and gender were similar between the groups (Table 4). 
Table 1. Pathogenic and likely pathogenic variants

\begin{tabular}{|c|c|c|c|c|c|c|c|c|c|c|}
\hline & Gene & Transcript & Variation & $\begin{array}{c}\text { Variation } \\
\text { Type }\end{array}$ & Status & $\mathrm{dbSNP}$ & ClinVar & $\begin{array}{c}\text { Classification } \\
\text { ACMG }\end{array}$ & HGMD & References \\
\hline 1 & GCK & NM_000162 & $\begin{array}{c}\text { c. } 214 G>A \\
\text { (p.Gly72Arg) }\end{array}$ & Missense & PR & rs193922289 & $P$ & $\mathrm{P}$ & CM023383 & $\begin{array}{c}\text { Lehto } \\
\text { et al., } 1999 \text { (23) }\end{array}$ \\
\hline 2 & GCK & NM_000162 & $\begin{array}{c}\text { c.506A>G } \\
\text { (p.Lys169Arg) }\end{array}$ & Missense & PR & - & - & $L P$ & CM141531 & $\begin{array}{c}\text { Flanagan } \\
\text { et al., } 2014 \text { (24) }\end{array}$ \\
\hline 3 & GCK & NM_000162 & $\begin{array}{c}\text { c.572G>A } \\
\text { (p.Arg191Gln) }\end{array}$ & Missense & PR & rs886042610 & LP/NUS & $L P$ & CM012120 & $\begin{array}{c}\text { Massa } \\
\text { et al., } 2001 \text { (25) }\end{array}$ \\
\hline 4 & GCK & NM_000162 & $\begin{array}{c}\text { c.775G }>A \\
\text { (p.Ala259Thr) }\end{array}$ & Missense & PR & rs1375656631 & $\mathrm{P}$ & $P$ & CM980894 & $\begin{array}{c}\text { Hattersley } \\
\text { et al., } 1998 \text { (26) }\end{array}$ \\
\hline 5 & GCK & NM_000162 & $\begin{array}{c}\text { c.898G>A } \\
\text { (p.Glu300Lys) }\end{array}$ & Missense & PR & rs1255911887 & - & LP & CM930305 & $\begin{array}{c}\text { Froguel } \\
\text { et al., } 1993(27)\end{array}$ \\
\hline 6 & GCK & NM_000162 & $\begin{array}{c}c .943 C>T \\
\text { (p.Leu315Phe) }\end{array}$ & Missense & PR & - & - & $L P$ & CM064013 & $\begin{array}{c}\text { Vits } \\
\text { et al., } 2006 \text { (28) }\end{array}$ \\
\hline 7 & HNF1A & NM_000545 & $\begin{array}{c}\text { c.392G>A } \\
\text { (p.Arg131GIn) }\end{array}$ & Missense & PR & rs753998395 & P & LP & CM961361 & $\begin{array}{c}\text { Yamagata } \\
\text { et al., 1996(29) }\end{array}$ \\
\hline 8 & HNF1B & NM_000458 & $\begin{array}{c}\text { c.1390G>C } \\
\text { (p.Gly464Arg) }\end{array}$ & Missense & Novel & - & - & $L P$ & - & - \\
\hline 9 & HNF4A & NM_001030003 & $\begin{array}{c}\text { c.110T>C } \\
\text { (p.Leu37Pro) }\end{array}$ & Missense & Novel & - & - & $\mathrm{LP}$ & - & - \\
\hline 11 & HNF4A & NM_001030003 & $\begin{array}{l}\text { c.1097C>G } \\
\text { (p.Pro366Arg) }\end{array}$ & Missense & PR & rs193922469 & LP & $L P$ & - & - \\
\hline 12 & $A B C C 8$ & NM_000352 & $\begin{array}{l}\text { c. } 1616 A>G \\
\text { (p. Tyr539Cys) }\end{array}$ & Missense & PR & rs193922397 & $L P$ & $L P$ & - & - \\
\hline 13 & $A B C C 8$ & NM_000352 & $\begin{array}{c}\text { c. } 4055 \mathrm{G}>\mathrm{A} \\
\text { (p.Arg1352His) }\end{array}$ & Missense & PR & rs28936370 & $P$ & $\mathrm{P}$ & CM042667 & $\begin{array}{c}\text { Magge } \\
\text { et al., } 2004 \text { (30) }\end{array}$ \\
\hline 14 & $A B C C 8$ & NM_000352 & $\begin{array}{l}\text { c.4306C>T } \\
\text { (p.Arg1436*) }\end{array}$ & Nonsense & PR & rs193922402 & $P$ & $P$ & CM112832 & $\begin{array}{c}\text { Powell } \\
\text { et al., } 2011 \text { (31) }\end{array}$ \\
\hline 15 & $A B C C 8$ & NM_000352 & $\begin{array}{c}\text { c.4631G>C } \\
\text { (p.Ser1544Thr) }\end{array}$ & Missense & Novel & - & - & $L P$ & - & - \\
\hline 16 & KCNJ11 & NM_000525 & $\begin{array}{c}c .841 \mathrm{C}>\mathrm{T} \\
\text { (p.Leu281Phe) }\end{array}$ & Missense & Novel & - & - & $L P$ & - & - \\
\hline 17 & KCNJ11 & NM_000525 & $\begin{array}{c}c .1019 \mathrm{C}>\mathrm{A} \\
\text { (p.Pro340His) }\end{array}$ & Missense & PR & - & - & $L P$ & CM144523 & $\begin{array}{c}\text { Mohnike } \\
\text { et al., } 2014 \text { (33) }\end{array}$ \\
\hline 18 & KCNJ11 & NM_000525 & $\begin{array}{l}\text { c.1084G>A } \\
\text { (Ala362Thr) }\end{array}$ & Missense & PR & rs755839409 & - & $L P$ & CM182438 & $\begin{array}{c}\text { Mohan } \\
\text { et al., } 2018 \text { (32) }\end{array}$ \\
\hline
\end{tabular}

PR: previously reported; P: pathogenic; LP: likely pathogenic; VUS: variant of uncertain significance.

Table 2. Pathogenicity evaluation of novel variations

\begin{tabular}{|c|c|c|c|c|c|c|c|c|c|}
\hline & $\begin{array}{c}\text { Gene } \\
\text { (Transcript ID) }\end{array}$ & Variation & $\begin{array}{l}\text { Family } \\
\text { History }\end{array}$ & Segregation & $\begin{array}{l}\text { Mutation } \\
\text { Taster }\end{array}$ & SIFT & DANN Score & GnomAD & Pathogenicity \\
\hline 1 & $\begin{array}{c}\text { HNF1B } \\
\text { (NM_000458) }\end{array}$ & $\begin{array}{c}\text { c.1390G>C } \\
\text { (p.Gly464Arg) }\end{array}$ & + & Compatible & $\begin{array}{l}\text { Disease } \\
\text { Causing }\end{array}$ & Damaging & 0.9986 & 0 & $L P$ \\
\hline 2 & $\begin{array}{c}\text { HNF4A } \\
\text { (NM_001030003) }\end{array}$ & $\begin{array}{c}\text { c.110T>C } \\
\text { (p.Leu37Pro) }\end{array}$ & - & $N / A$ & $\begin{array}{l}\text { Disease } \\
\text { Causing }\end{array}$ & Damaging & 0.9964 & 0 & LP \\
\hline 3 & $\begin{array}{c}\text { ABCC8 } \\
\text { (NM_000352) }\end{array}$ & $\begin{array}{c}\text { c.4631G>C } \\
\text { (p.Ser1544Thr) }\end{array}$ & + & Compatible & $\begin{array}{l}\text { Disease } \\
\text { Causing }\end{array}$ & Tolerated & 0.9672 & 0 & $L P$ \\
\hline 4 & $\begin{array}{c}\text { KCNJ11 } \\
\text { (NM_000525) }\end{array}$ & $\begin{array}{c}c .841 \mathrm{C}>\mathrm{T} \\
\text { (p.Leu281Phe) }\end{array}$ & + & Compatible & $\begin{array}{l}\text { Disease } \\
\text { Causing }\end{array}$ & Tolerated & 0.9729 & 0 & $L P$ \\
\hline
\end{tabular}


Diabetes diagnosis age was younger in the MODY $(+)$ group, but the difference was not statistically significant. Sixty-six percent of MODY (+) subjects had diabetes history for 3 consecutive generations in their family, compared to $32 \%$ of T2DM patients, which was statistically significant $(p=0.008)$. The groups were similar in terms of diabetes complications. Pharmacologic treatment modalities were not very different between the groups, but we found that MODY $(+)$ patients tended to start insulin therapy at a younger age than the negative group-did; thus, their insulin duration time was longer than that of the negative group, although their insulin doses were lower than the T2DM group. We evaluated all patients according to concomitant comorbidities such as hypertension, hyperlipidemia, and hepatosteatosis. More patients in the T2DM group had hypertension (40\%) than in the MODY $(+)$ group $(7.7 \%)$, which was statistically significant $(p=0.007)$. Other comorbidities were similar between the groups (Table 4).

Table 3. Comparison of laboratory parameters of the groups

\begin{tabular}{lccc}
\hline & MODY (n:27) & T2DM (n:25) & p-value \\
\hline C-peptide & $1.60(0.01-3.18)$ & $1.78(0.65-4.78)$ & 0.145 \\
FPG (mg/dL) & $112(82-366)$ & $109(74-329)$ & 0.440 \\
HbA1c (\%) & $6.70(5.8-10.5)$ & $7(5.4-14.6)$ & 0.962 \\
LDL & $101(38-201)$ & $115(83-212)$ & 0.068 \\
HDL & $49(26-65)$ & $45(27-68)$ & 0.283 \\
Trig & $91(32-558)$ & $120(37-381)$ & 0.180 \\
U acid & $4.70(2.80-6.40)$ & $4.80(1.80-7.56)$ & 0.705 \\
Crea & $0.61(0.21-0.96)$ & $0.69(0.36-2.63)$ & 0.118 \\
GFR & $143.79(55.56-315)$ & $114.26(62.03-1725)$ & 0.213 \\
Microalbuminuria & $43(32-52)$ & $43(37-52)$ & 0.842 \\
Ca & $9.40(8.3-10.3)$ & $9.50(8.8-10.8)$ & 0.355 \\
P & $3.20(2-5)$ & $3.40(2-4.6)$ & 0.573 \\
PTH & $39.13(18.90-83.27)$ & $38.53(10.11-58.13)$ & 0.848 \\
Vitamin D & $16.82(7.03-43)$ & $15.54(4.72-48.77)$ & 0.952 \\
\hline
\end{tabular}

Table 4. Comparison of the groups according to demographic results and history of diabetes

\begin{tabular}{|c|c|c|c|}
\hline & MODY (n:27) & T2DM (n:25) & p-value \\
\hline \multicolumn{4}{|l|}{ Gender (F/M) } \\
\hline Female & $11(40.7 \%)$ & $14(56 \%)$ & \multirow{2}{*}{0.271} \\
\hline Male & $16(59.3 \%)$ & $11(44 \%)$ & \\
\hline Age (years) & $34.22 \pm 16.26$ & $40.96 \pm 11.77$ & 0.092 \\
\hline BMI (kg/m2) & $28.64(20.3-44.1)$ & $27.63(20.36-52.49)$ & 0.624 \\
\hline DM diagnosis age & $28.11 \pm 16.41$ & $33.40 \pm 11.69$ & 0.185 \\
\hline 3 generation DM & $18(66.6 \%)$ & $8(32 \%)$ & 0.008 \\
\hline Retinopathy (n) & 0 & $3(12 \%)$ & 1 \\
\hline Nephropathy (n) & $4(15.4 \%)$ & $6(24 \%)$ & 0.499 \\
\hline Neuropathy (n) & $2(7.7 \%)$ & $4(16 \%)$ & 0.419 \\
\hline OAD & $1(1-3)$ & $1(1-3)$ & 0.725 \\
\hline OAD duration (years) & $6.50(1-23)$ & $3(1-20)$ & 0.138 \\
\hline Insulin starting age (years) & $21.82 \pm 10.74$ & $32.43 \pm 10.54$ & 0.021 \\
\hline Insulin duration (years) & $11(2-23)$ & $5(1-16)$ & 0.231 \\
\hline$<0.5 \mathrm{JU} / \mathrm{kg}$ insulin requirement (n) & $17(73.9 \%)$ & $16(69.6 \%)$ & 0.743 \\
\hline Hypertension (n) & $2(7.7 \%)$ & $10(40 \%)$ & 0.007 \\
\hline Hepatosteatosis (n) & $9(34.6 \%)$ & $8(32 \%)$ & 0.843 \\
\hline Hyperlipidemia (n) & $3(11.5 \%)$ & 7 (28\%) & 0.173 \\
\hline
\end{tabular}




\section{DISCUSSION}

In this study, we analyzed the accuracy and parallelism of our mutation-requesting criteria with the presence of mutations among adult diabetic patients, and also compared the clinical and laboratory results of mutation (+) and (-) groups. We found MODY mutation positivity in $40.3 \%$ of all study subjects and the most common mutation was GCK (44.4\%) in our study population. The frequency of MODY in T2DM patients varies by country, with $21 \%$ in the USA, $27 \%$ in the UK, $31 \%$ in Norway, 39\% in the Netherlands, $19 \%$ in Japan, and to our knowledge, 29\% in the Turkish pediatric population $(17,34)$. MODY subtype frequencies vary by region. Haliloglu and cols. (17) showed that the most common MODY mutation is GCK in pediatric diabetic patients in Turkey (almost 25\%), whereas in the SEARCH study HNFIA mutation was found to be the most common MODY subtype among the young diabetic population in the USA (10). Almost all studies about MODY were performed in pediatric groups, and the most common MODY subtype was usually the GCK mutation in European countries, higher than in Asian countries such as Japan and Korea $(35,36)$. In our study, pathologic $G C K$ mutations were the most common, followed by HNF4A mutations in the adult MODY $(+)$ group; similar to what was found in the pediatric population in Turkey. These results are consistent with the distribution in other Southern European populations $(15,34,37)$.

Genetic testing is the gold standard for diagnosing MODY and it can be utilized for planning a treatment strategy according to the mutation type. However, genetic testing is often expensive and widely accessible. Thus, careful consideration is required when determining which patients need to undergo genetic testing. According to the results of some studies, most of which were conducted in childhood diabetes patients, some criteria were established, and genetic analysis was recommended for patients who met these criteria. Shields and cols. (3) developed a prediction model to determine the probability of MODY in patients with young-onset diabetes. They predicted that positive C-peptides and negative autoantibodies were strongly suggestive of MODY compared to TIDM. On the other hand, they claimed that the presence of insulin resistance and high BMI could be clinical markers for T2DM.

MODY is a genetically heterogeneous disease and to date 14 genes (GCK, HNFIA, HNF4A, HNFIB, INS,
KCNJ11, ABCC8, PDXI, NEURODI, KLFI1, CEL, PAX4, BLK and APPLI) were associated with MODY. However, GCK and HNFIA mutations are detected in approximately half of the MODY patients (25). We detected four novel variations which were predicted to be likely pathogenic according to the ACMG guidelines. None of these four novel variations were reported in population studies (GnomAD) and they were not present in 200 Turkish control chromosomes. The novel likely pathogenic variants were analyzed using in silico analysis tools stated in Table 2. Family members were screened for the detected variations and it was shown that related variations co-segregated with the disease in three families. However, the patient carrying the HNF4A c.110T>C (p.Leu37Pro) variation declared that no family members were diagnosed as MODY and we were not able to screen the parents for MODY. In total, 180 variations were reported in The Human Gene Mutation Database Professional in HNF4A gene of which most are missense variations. There are several studies reporting molecular findings in MODY cases in Turkish or other populations. However, it is still possible to encounter novel variations due to high allelic heterogeneity in $\operatorname{MODY}(26,27)$.

Few studies have compared adult T2DM patients with MODY patients in terms of clinical and laboratory parameters. Chambers and cols. (38) compared 75 MODY (-) and 22 MODY (+) patients. The positive group had a lower HbAlc, and their family history of diabetes was significantly longer; most of them had not undergone any pharmacological treatment. According to these findings, they reported that MODY could be suspected in youth diabetes patients with negative antibodies and preserved C-peptides. Zhang and cols. (11) reported that MODY $(+)$ Chinese patients were younger at diagnosis, and had a longer duration of diabetes, higher fasting plasma glucose, lower C-peptides, lower BMI, lower HOMA and lower triglycerides compared with early-onset T2DM patients. A recent study on 263 Japanese patients (35) showed that mutation-positive patients had a lower BMI and insulin resistance compared to mutation-negative diabetics; and were also younger at the time of the diagnosis. Based on previous studies, Jang (39) suggests MODY genetic analysis in adult diabetic patients if they were diagnosed before the age of 30 , if $\beta$-cell antibodies are negative, and if they have a family history of diabetes and $\mathrm{BMI} \leq 30 \mathrm{~kg} / \mathrm{m}^{2}$ without insulin resistance. 
In our study, family history was the most significant distinguishing feature among the clinical MODY diagnosis criteria. MODY (+) subjects had a significantly long diabetes history of 3 consecutive generations in their family $(66 \%)$ compared to T2DM patients $(32 \%)$ $(p=0.008)$. Diabetes diagnosis age was younger in the MODY (+) group compared to the mutation-negative group, but this difference was not statistically significant ( $p=0.092)$. Since most patients with the GCK mutation can continue without treatment for many years, the age of diagnosis may be advanced. In our study, we have found that the age of diagnosis of the MODY (+) group was higher than expected. This might be caused by the presence of GCK mutation in the majority of the patients and the fact that some of these patients were incidentally diagnosed by genetic analysis when their first degree relatives were diagnosed with mutation-positive T2DM. Contrary to other studies, we found no significant differences in C-peptides, BMI, or HbAlc between the groups. Similarly, in another study from Korea (36) comparing 23 mutation-positive patients with 17 earlyonset T2DM patients in terms of clinical and metabolic profiles, no differences were found for age at diagnosis, BMI, C-peptides, and fasting and postprandial glucose levels. Interestingly, we found that mutation-positive patients start insulin therapy at younger ages than the T2DM patients. On the other hand, we had expected that GCK mutation-positive patients would not need any treatment for a long time. This could be because other mutations may cause uncontrolled aggressive hyperglycemia. In our study population, hypertension was the unique comorbidity accompanying to diabetes in mutation-negative patients. Although microvascular complication frequency was quite higher in T2DM patients, there were no statistically differences between the groups according to diabetes complications, duration of diabetes, or insulin usage.

All these study results show that previously suggested diagnostic criteria for MODY $(10,40,41)$ might not be sufficient to predict MODY patients. According to current studies, C-peptide level seems to be more of an important criterion for TIDM. No difference was found in our patient group in terms of HbAlc and BMI; thus, they might not be sufficient criteria to predict MODY alone. According to the present study results, MODY mutation positivity is most probable in young autoantibody negative diabetes patients diagnosed before 30 years of age; who have a first-degree family history of diabetes. Screening for
MODY would be an appropriate approach in young patients who typically do not fit the T2DM profile and have a first-degree family history of diabetes.

One limitation of our study was the small number of patients because we only recruited patients who were suspected of MODY and who were referred for genetic analysis. Therefore, we did not define specific inclusion criteria for the patients. Another limitation of our study was that all existing mutations could not be examined. We screened for the single nucleotide variations ( $\mathrm{SNVs}$ ) and small deletions or insertions in only 7 of these genes' coding regions. We were not able to exclude the copy number variations (CNVs), variations in noncoding regions of these genes and the rest of the MODY related genes in MODY (-) group.

In conclusion, according to the results of this study, it would be meaningful to investigate MODY mutations in T2DM patients who were diagnosed before the age of 30 , who have a family history of diabetes in their firstdegree relatives, and who are autoantibody negative. Other parameters are not very valuable for screening MODY mutation in every young diabetic patient.

Disclosure: no potential conflict of interest relevant to this article was reported.

\section{REFERENCES}

1. Henzen C. Monogenic diabetes mellitus due to defects in insulin secretion. Swiss Med Wkly. 2012;142:w13690.

2. Shepherd M, Shields B, Hammersley S, Hudson M, McDonald TJ, Colclough K, et al. Systematic Population Screening, Using Biomarkers and Genetic Testing, Identifies 2.5\% of the U.K. Pediatric Diabetes Population With Monogenic Diabetes. Diabetes Care. 2016;39(11):1879-88.

3. Shields BM, McDonald TJ, Ellard S, Campbell MJ, Hyde C, Hattersley AT. The development and validation of a clinical prediction model to determine the probability of MODY in patients with young-onset diabetes. Diabetologia. 2012;55(5):1265-72.

4. Froguel P, Vaxillaire M, Sun F, Velho G, Zouali H, Butel MO, et al. Close linkage of glucokinase locus on chromosome $7 p$ to early-onset non-insulin-dependent diabetes mellitus. Nature. 1992;356(6365):162-4.

5. Yamagata K, Furuta H, Oda N, Kaisaki PJ, Menzel S, Cox NJ, et al. Mutations in the hepatocyte nuclear factor-4alpha gene in maturity-onset diabetes of the young (MODY1). Nature. 1996;384(6608):458-60.

6. HorikawaY, Iwasaki N, Hara M, Furuta H, HinokioY, Cockburn BN, et al. Mutation in hepatocyte nuclear factor-1 beta gene (TCF2) associated with MODY. Nat Genet. 1997;17(4):384-5.

7. Kim SH. Maturity-Onset Diabetes of theYoung:What Do Clinicians Need to Know? Diabetes Metab J. 2015;39(6):468-77.

8. Urakami T. Maturity-onset diabetes of the young (MODY): current perspectives on diagnosis and treatment. Diabetes Metab Syndr Obes. 2019;12:1047-56. 
9. Shields BM, Hicks S, Shepherd MH, Colclough K, Hattersley AT, Ellard S. Maturity-onset diabetes of the young (MODY): how many cases are we missing? Diabetologia. 2010;53(12):2504-8.

10. Pihoker C, Gilliam LK, Ellard S, Dabelea D, Davis C, Dolan LM, et al. Prevalence, characteristics and clinical diagnosis of maturity onset diabetes of the young due to mutations in HNF1A, HNF4A, and glucokinase: results from the SEARCH for Diabetes in Youth. J Clin Endocrinol Metab. 2013;98(10):4055-62.

11. Zhang M, Zhou JJ, Cui W, Li Y, Yang P, Chen X, et al. Molecular and phenotypic characteristics of maturity-onset diabetes of the young compared with early onset type 2 diabetes in China. $J$ Diabetes. 2015;7(6):858-63.

12. WędrychowiczA, Tobór E, Wilk M, Ziółkowska-Ledwith E, Rams A, Wzorek K, et al. Phenotype Heterogeneity in GlucokinaseMaturity-Onset Diabetes of the Young (GCK-MODY) Patients. J Clin Res Pediatr Endocrinol. 2017;9(3):246-52.

13. Şıklar Z, de Franco E, Johnson MB, Flanagan SE, Ellard S, Ceylaner S, et al. Monogenic Diabetes Not Caused By Mutations in Mody Genes: A Very Heterogenous Group of Diabetes. Exp Clin Endocrinol Diabetes. 2018;126(10):612-8.

14. Hattersley AT, Greeley SAW, Polak M, Rubio-Cabezas O, Njølstad PR, Mlynarski W, et al. ISPAD Clinical Practice Consensus Guidelines 2018: The diagnosis and management of monogenic diabetes in children and adolescents. Pediatr Diabetes. 2018;19 Suppl 27:47-63.

15. Kavvoura FK, Owen KR. Maturity onset diabetes of the young: clinical characteristics, diagnosis and management. Pediatr Endocrinol Rev. 2012;10(2):234-42.

16. Wilmot $E$, Idris I. Early onset type 2 diabetes: risk factors, clinical impact and management. Ther Adv Chronic Dis. 2014;5(6):234-44.

17. Haliloglu B, Hysenaj G, Atay Z, GuranT, Abalı S,Turan S, et al. GCK gene mutations are a common cause of childhood-onset MODY (maturity-onset diabetes of the young) in Turkey. Clin Endocrinol (Oxf). 2016;85(3):393-9.

18. Colclough K, Bellanne-Chantelot C, Saint-Martin C, Flanagan $\mathrm{SE}$, Ellard S. Mutations in the genes encoding the transcription factors hepatocyte nuclear factor 1 alpha and 4 alpha in maturityonset diabetes of the young and hyperinsulinemic hypoglycemia. Hum Mutat. 2013;34(5):669-85.

19. Beysel S, Eyerci N, Pinarli FA, Kizilgul M, Ozcelik O, Caliskan M, et al. HNF1A gene p.I27L is associated with early-onset, maturityonset diabetes of the young-like diabetes in Turkey. BMC Endocr Disord. 2019;19(1):51.

20. Richards S, Aziz N, Bale S, Bick D, Das S, Gastier-Foster J, et al. Standards and guidelines for the interpretation of sequence variants: a joint consensus recommendation of the American College of Medical Genetics and Genomics and the Association for Molecular Pathology. Genet Med. 2015;17(5):405-24.

21. Quang D, Chen $Y, X i e X$. DANN: a deep learning approach for annotating the pathogenicity of genetic variants. Bioinformatics. 2015;31(5):761-3.

22. Lek M, Karczewski KJ, Minikel EV, Samocha KE, Banks E, Fennell $T$, et al. Analysis of protein-coding genetic variation in 60,706 humans. Nature. 2016;536(7616):285-91.

23. Lehto $M$, Wipemo $C$, Ivarsson $S A$, Lindgren $C$, Lipsanen-Nyman $\mathrm{M}$, Weng $\mathrm{J}$, et al. High frequency of mutations in MODY and mitochondrial genes in Scandinavian patients with familial earlyonset diabetes. Diabetologia. 1999;42(9):1131-7.

24. Flanagan $\mathrm{SE}$, De Franco $\mathrm{E}$, Lango Allen $\mathrm{H}$, Zerah $\mathrm{M}$, Abdul-Rasoul $\mathrm{MM}$, Edge JA, et al. Analysis of transcription factors key for mouse pancreatic development establishes NKX2-2 and MNX1 mutations as causes of neonatal diabetes in man. Cell Metab. 2014;19(1):146-54.
25. Massa O, Meschi F, Cuesta-Munoz A, Caumo A, Cerutti F, Toni $S$, et al. High prevalence of glucokinase mutations in Italian children with MODY. Influence on glucose tolerance, first-phase insulin response, insulin sensitivity and BMI. Diabetologia. 2001;44(7):898-905.

26. Hattersley AT, Beards F, Ballantyne E, Appleton M, Harvey R, Ellard S. Mutations in the glucokinase gene of the fetus result in reduced birth weight. Nat Genet. 1998;19(3):268-70.

27. Froguel $\mathrm{P}$, Zouali $\mathrm{H}$, Vionnet $\mathrm{N}$, Velho $\mathrm{G}$, Vaxillaire $\mathrm{M}$, Sun $\mathrm{F}$, et al. Familial hyperglycemia due to mutations in glucokinase. Definition of a subtype of diabetes mellitus. N Engl J Med. 1993;328(10):697-702.

28. Vits L, Beckers D, Craen M, de Beaufort C, Vanfleteren E, Dahan K, et al. Identification of novel and recurrent glucokinase mutations in Belgian and Luxembourg maturity onset diabetes of the young patients. Clin Genet. 2006;70(4):355-9.

29. Yamagata K, Oda N, Kaisaki PJ, Menzel S, Furuta H, Vaxillaire $\mathrm{M}$, et al. Mutations in the hepatocyte nuclear factor-1alpha gene in maturity-onset diabetes of the young (MODY3). Nature. 1996;384(6608):455-8.

30. Magge SN, Shyng SL, MacMullen C, Steinkrauss L, Ganguly A, Katz LE, et al. Familial leucine-sensitive hypoglycemia of infancy due to a dominant mutation of the beta-cell sulfonylurea receptor. J Clin Endocrinol Metab. 2004;89(9):4450-6.

31. Powell PD, Bellanné-Chantelot $C$, Flanagan SE, Ellard S, Rooman $R$, Hussain $K$, et al. In vitro recovery of ATP-sensitive potassium channels in $\beta$-cells from patients with congenital hyperinsulinism of infancy. Diabetes. 2011;60(4):1223-8.

32. Mohan V, Radha V, Nguyen TT, Stawiski EW, Pahuja KB, Goldstein $\mathrm{LD}$, et al. Comprehensive genomic analysis identifies pathogenic variants in maturity-onset diabetes of the young (MODY) patients in South India. BMC Med Genet. 2018;19(1):22.

33. Mohnike K, Wieland I, Barthlen W, Vogelgesang S, Empting S, Mohnike W, et al. Clinical and genetic evaluation of patients with KATP channel mutations from the German registry for congenital hyperinsulinism. Horm Res Paediatr. 2014;81(3):156-68.

34. Kleinberger JW, Pollin TI. Undiagnosed MODY: Time for Action. Curr Diab Rep. 2015;15(12):110.

35. YorifujiT, Higuchi S, Kawakita R, HosokawaY, AoyamaT, Murakami A, et al. Genetic basis of early-onset, maturity-onset diabetes of the young-like diabetes in Japan and features of patients without mutations in the major MODY genes: Dominance of maternal inheritance. Pediatr Diabetes. 2018;19(7):1164-72.

36. Hwang JS, Shin $\mathrm{CH}$, Yang SW, Jung SY, Huh N. Genetic and clinical characteristics of Korean maturity-onset diabetes of the young (MODY) patients. Diabetes Res Clin Pract. 2006;74(1):75-81.

37. Estalella I, Rica I, Perez de Nanclares G, Bilbao JR, Vazquez JA, San Pedro Jl, et al. Mutations in GCK and HNF-1alpha explain the majority of cases with clinical diagnosis of MODY in Spain. Clin Endocrinol (Oxf). 2007;67(4):538-46.

38. Chambers C, Fouts A, Dong F, Colclough K, Wang Z, Batish SD, et al. Characteristics of maturity onset diabetes of the young in a large diabetes center. Pediatr Diabetes. 2016;17(5):360-7.

39. Jang KM. Maturity-onset diabetes of the young: update and perspectives on diagnosis and treatment. Yeungnam Univ J Med. 2020;37(1):13-21.

40. Thanabalasingham G, Pal A, Selwood MP, Dudley C, Fisher K, Bingley PJ, et al. Systematic assessment of etiology in adults with a clinical diagnosis of young-onset type 2 diabetes is a successful strategy for identifying maturity-onset diabetes of the young. Diabetes Care. 2012;35(6):1206-12.

41. Stanik J, Dusatkova P, Cinek O, Valentinova L, Huckova M, Skopkova M, et al. De novo mutations of GCK, HNF1A and HNF4A may be more frequent in MODY than previously assumed. Diabetologia. 2014;57(3):480-4. 